\title{
Identifikasi Pola Asuh Orangtua di Kota Pontianak
}

\author{
Rinda Nikenindiana Sukamto ${ }^{\bowtie}$, Pujiyanti Fauziah ${ }^{2}$ \\ Pendidikan Anak Usia Dini, Universitas Negeri Yogyakarta \\ DOI: $\underline{10.31004 / \text { obsesi.v5i1.638 }}$
}

\begin{abstract}
Abstrak
Tujuan penelitian ini adalah untuk mengidentifikasi pola asuh pada anak usia 4-8 tahun di kota Pontianak. Pendekatan penelitian ini adalah pendekatan deskriptif dengan jenis penelitian deskriptif kuantitatif. Sampel yang diteliti adalah 90 responden yang memiliki anak berusa 4-8 tahun yang ada di sekitar kota Pontianak. Data penelitian tersebut dikumpulkan dengan menggunakan angket yang di sebar secara online atau biasa di sebut google form. Hasil penelitian adalah dari 90 responden yang tersebar di kota Pontianak yang menerapkan pola asuh demokratis adalah sebesar $88,80 \%$ atau sekitar 80 responden yang menggunakan pola asuh demokratis, sedangkan pola asuh otoriter ada $4,44 \%$ atau sebanyak 4 responden dan untuk pola asuh permisif ada $4,44 \%$ atau sebanyak 6 responden. Hasil tersebut di dapat dari membandingkan ke tiga jenis pola asuh tersebut mana yang lebih dominan untuk gaya pengasuhannya. Dapat di simpulkan bahwa dari 90 responden 80 orang tua menerapkan pola asuh demokratis dalam pola asuh di Kota Pontianak.
\end{abstract}

Kata Kunci: identifikasi, pola asuh orang tua, anak usia dini.

\begin{abstract}
The purpose of this study is to indentify the parenting in children aged 4-8 years in the Pontianak city. This research is quantitative descriptive research. Samples obtained were 90 respondents who have 4-8-year-old children who are around the city of Pontianak. The research data was collected using online or commonly called google forms questionnaire. The results of the study were of 90 respondents spread in Pontianak who adopted parenting, a contribution of $88.80 \%$ or around 80 respondents using parenting, while there were $4.44 \%$ authoritarian parenting or 4 respondents and for permissive parenting there were $666 \%$ or 6 respondents. The result was to compare three types of parenting which are more dominant for their parenting style. It can be concluded from 90 respondents 80 parents applied the approved parenting in Pontianak City.
\end{abstract}

Keywords: identification, parenting, early childhood.

Copyright (c) 2020 Rinda Nikenindiana Sukamto, Pujiyanti Fauziah

$\square$ Corresponding author:

Email Address : rinda.nikenindiana@gmail.com ( Yogyakarta, Indonesia )

Received tanggal bulan tahun, Accepted tanggal bulan tahun, Published tanggal bulan tahun

\section{PENDAHULUAN}

Masa usia dini adalah masa terbaik atau yang biasa disevut masa emas (golden age) bagi perkembangan, karena pada masa ini perkembangan anak berkembang begitu pesat(Osborn \& White, 2018)Anak usia dini berada pada proses pertumbuhan dan perkembangan, orang tua berperan penting dalam proses pertumbuhan dan perkembangan anak dan 
perkembangan anak harus dikembangkan secara optimal dan maksimal. Perkembangan anak akan tumbuh dan berkembang secara optimal dan maksimal apabila distimulasi dengan cara yang tepat disesuai dengan tingkat perkembangan setiap anak. Pendidikan berlangsung pertama kalinya di lingkungan keluarga. Keluarga adalah lingkungan dalam satu atap, keinginan untuk hidup bersama dalam satu rumah dan berpotensi mempunyai anak membentuk komunitas baru yang disebut keluarga (Rahmah, 2019). Pola asuh yang diberikan orang tua adalah pendidikan pertama bagi seorang anak karena pertama kalinya mereka mengenal dunia dan terlahir di lingkungan keluarga dan dididik oleh orang tua. Keteladanan orang tua dalam tindakan sehari-hari akan menjadi wahana pendidikan moral bagi anak, membentuk anak sebagai makhluk sosial, religius untuk menciptakan kondisi yang dapat menumbuh kembangkan inisiatif dan kreatifitas anak (Santosa et al., 2018). Pola asuh merupakan tata cara yang diterapkan orang tua dalam mengasuh, merawat, melindungi dan mendidik anak-anaknya(Persepsi et al., 2019).

Pola asuh orang tua merupakan suatu interaksi antara orang tua dan anak, dimana orang tua bermaksud menstimulasi anaknya dengan mengubah tingkah laku, pengetahuan serta nilai-nilai yang dianggap paling tepat oleh orang tua, agar anak dapat mandiri, tumbuh dan berkembang secara sehat dan optimal (Kemandirian et al., 2014). Anak memiliki gambaran tentang prinsip-prinsip kehidupan yang ditentukan oleh proses pola asuh (Djuwitaningsih, 2018). Pola pengasuhan dari orang tua merupakan perilaku yang ditetapkan kepada anak bersifat flexibel dari waktu ke waktu (Dayak \& Kabupaten, 2017) (Education et al., 2015)). Pengasuhan anak merupakan suatu kegiatan berkelanjutan melalui proses interaksi orang tua dan anak untuk mendorong pertumbuhan serta perkembangan anak yang optimal (Rakhmawati, n.d.). Pola pengasuhan yang dilakukan oleh oran tua memegang peranan yang sangat penting bagi perkembangan anak. Menurut (Candra et al., n.d.)menyatakan bahwa pengasuhan orang tua terhadap anaknya dapat berpengaruh terhadap pembentukan karakter dan perilaku anak itu sendiri. Pola asuh yang tepat bagi anak dan sesuai dengan kebutuhan anak akan memungkinkan dukungan positif diterima oleh anak. Pola asuh yang positif ini sangat mendukung pembentukan kepribadian yang mandiri dan semangat belajar (Dewi et al., 2020). Pola prilaku ini dirasakan oleh anak mau itu positif ataupun negative. Di dalam pola pengasuhan terdapat gaya dalam pengasuhan, disetiap keluarga pasti berbeda beda tergantung dari pandangan orang tua. Menurut Woolfolk (Ekasari \& Witarsa, 2018)terdapat tiga jenis pola pengasuhan orang tua yang secara umum yaitu pola pengasuhan demokratis, otoriter dan permisif.

Pola asuh demokratis adalah pola asuh yang memprioritaskan kepentingan anak, akan tetapi tidak ragu dalam mengendalikan anak (Padjrin, 2016)Pola asuh ini memberikan tempat atau ruang untuk anak dalam memberikan gagasan atau masukannya mengenai pendapat atau keinginan anak Alviana (2013). Keputusan anak turut dipertimbangkan dalam pengambilan keputusan dalam, komunikasi bersifat dua arah atau terbuka aturan yang telah ditetapkan berdasarkan keputusan bersama antara anak dan orang tua. Pola asuh demokratis salah bentuk perlakuan yang dapat diterapkan orang tua untuk membentuk kepribadian anak dengan mengutamakan kepentingan anak (Suteja, 2017). Ciri-ciri pola asuh demokratis: memberikan pengarahan tentang perbuatan yang dipertahankan, yang baik dan perbuatan yang tidak baik agar di tinggalkan, menentukan kedisiplinan dan aturan-aturan tetapi mempertimbangkan agar dapat diterima dan dimengerti anak, menciptakan suasana komunikatif di dalam keluarga, menciptakan keharmonisan dalam keluarga.

Jika orang tua menggunakan pola asuh demokratis maka anak akan merasakan kasih sayang orang tuanya dan tidak merasa terkekang dan anak akan lebih bertanggung jawab dan mandiri dengan kehidupan nya (Yunita et al., 2020). Pola asuh demokratis orang tua bersikap acceptance dan mengontrol tinggi, bersikap responsive terhadap kebutuhan anak, mendorong anak untuk menyatakan pendapat, memberikan penjelasan tentang hal yang baik dan yang buruk, memberikan kebebasan anak memilih dan melakukan sebuah tindakan(Sofiani \& Sumarni, 2020). Untuk pola asuh kedua ada pola asuh otoriter bercirikan 
keras, kaku dan bersifat paksaan. Orang tua membuat aturan yang kaku dan aturan tersebut tidak di inginkan anak. ketika anak tidak mematuhi aturan yang sudah di buat, orang tua tidak segan untuk menghukum anak. Hukuman fisik hampir sama dengan pelecehan anak, jadi jika hukuman fisik dilakukan secara berlebihan itu bisa menjadi pelecehan anak (Olla et al., 2018). Menurut (Kemandirian et al., 2014)Perilaku anak yang mendapatkan pengasuhan otoriter cendrung bersikap mudah tersinggung, penakut pemurung selain itu tipe pengasuhan ini kurang kasih saying kepada anak, kurang simpatik dan anak cendrung sering disalahkan (Pratiwi, 2020). Pola asuh otoriter yang diterapkan oleh orang tua memiliki kelebihan yaitu menjadikan anak lebih patuh kepada orang tua sedangkan kelemahan nya anak menjadi kurang percaya diri dan kurang bebas, serta cendrung tidak mampu untuk mengeluarkan pendapatnya, anak mengalami kesulitan dalam berkomunikasi dengan orang lain(Hasanah, 2020).

Pola asuh yang ketiga adalah pola asuh permisif adalah pola asuh yang tidak perduli kepada anak. Pola asuh ini cendrung membebaskan anak, tidak mengendalikan anak, dan tidak memberikan hukuman bila anak melakukan kesalahan. Pola asuh ini biasa terjadi kepada orang tua yang sibuk bekerja. Orang tua yang menerapkan pola pengasuhan ini hanya akan memenuhi kebutuhan anak saja (Hazizah, 2019). Pola asuh permisif merupakan jenis pola asuh yang memberikan kebebasan anak tanpa adanya bimbingan dan tuntunan dari orang tua. Orang tua jarang melakukan control, orang tua juga tidak memantau kegiatan anak dan jarangnya komunikasi antara orang tua dan anak. Penelitian mengungkapkan bahwa anak yang dibesarkan dengan pengasuhan permisif aka sulit untuk bersosialisasi dengan lingkungannya (Juharta et al., 2015). Orang tuayang menggunakan pola asuh permisif tidak memberikan struktur batasan yang tepat bagi anak. Orang tua yang menggunakan tipe ini sangat mempercayai bahwa tidak adanya larangan dan mengekspresikan kebebas dari keinginan hati dan harapan sangatlah penting bagi perkembangan psikologi (Education et al., 2015)

Selain ketiga pola asuh tersebut ada dua factor yang mempengaruhi dalam pengasuhan seseorang yaitu factor eksternal dan factor internal. Factor eksternal adalah lingkungan social dan lingkungan fisik serta lingkungan kerja orang tua, sedangkan factor internal adalah model pola pengasuhan yang pernah didapat sebelumnya, secara lebih lanjut pembahasan factorfaktor yang ikut berpengaruh dalam pola asuh pengasuhan orang tua menurut (Sumarni \& Sofiani, 2019)adalah: budaya, orang tua mempertahankan konsep tradisional mengenai peran orang tua, sehigga tetap menggunakan cara pola pengasuhan orang tua dulu karena di anggap berhasil mendidik mereka dengan baik, tingkat pendidikan orang tua, orang tua lebih memiliki ilmu pengetahuan lebih banyak dalam mengasuh anak, status social ekonomi, orang tua dari kelas menengah cenderung lebih keras dalam mengasuh anak

Berdasarkan paparan di atas peneliti bertujuan untuk mengidentifikasi pola asuh apa yang sering digunakan orang tua di kota Pontianak. Subjek penelitian adalah orang tua yang berada di Pontianak .

\section{METODOLOGI}

Penelitian yang digunakan adalah penelitian deskriptif. Penelitian deskriptif adalah penelitian yang menggambarkan suatu situasi permasalahan dan menjelaskan permasalahan secara lebih lengkap Arikunto dalam (Vogt, 2015). Penelitian bermaksud menerangkan gejala dan tidak untuk menguji suatu hipotesis. Metode deskripsi, menganalisis, dan menyajikan data secara sistematis agar lebih mudah dipahami, kesimpulan yang dihasilkan dasarnya jelas. Kesimpulan berdasarkan angka yang telah di olah dan selanjutnya di analisis presentase . Penelitian ini bertujuan untuk menggambarkan suatu variable atau keadaan apa adanya dalam suatu situasi serta analisis datanya digambarkan dalam jumlah ukuran atau frekuensi. 


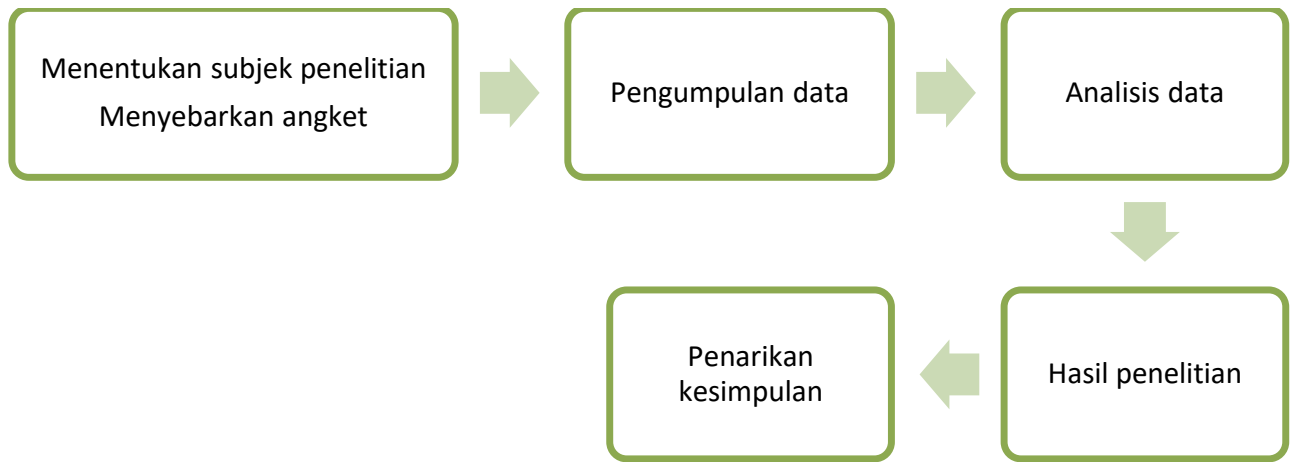

\section{Gambar 1. Alur Penelitian}

Penelitian ini dilakukan di Kota Pontianak, dengan menggunakan google form untuk orang tua yang memiliki anak usia 4-8 tahun serta menggunakan skala guttman, skala guttman digunakan untuk mendapatkan jawaban yang tegas, yaitu ya jika benar dan tidak jika tidak benar atau tidak sesuai. Data yang diperoleh dapat berupa data interval (Imron, 2019) Penelitian ini menggunakan google form/formulir. Jadi orang tua yang memiliki anak usia 4-8 tahun di kota Pontianak bisa mengisi google form tersebut. Selanjutnya Setelah data sudah terkumpul,lalu dilakukannya pengolahan data melalui tahap-tahap sebagai berikut: editing, mengoreksi suatu data yang diperoleh, coding, kegiatan pemberian angka tterhadap data yang terdiri dari beberapa katgori, scoring, memberikan sebuah nilai didasarkan pada kriteria yang telah ditetapkan, tabulating, pengumpulan data agar memudahkan dalam penjumlahan, disusun dan diatur selanjutnya disajikan dan dianalisis. Hidayat(2010).

Instrument yang digunakan dalam penelitian ini adalah skala guttmen. Instrumen penelitian adalah alat yang digunakan peneliti dalam mengumpulkan data agar pekerjaan lebih mudah dan menghasilkan suatu penelitian yang baik. Untuk kisi-kisi intstrumen saya megadopsi dari jurnal Jannah Identifikasi Pola Asuh Ditaman Kanak-Kanak Aba Yogyakarta yang sudah teruji validitas nya. Berikut kisi-kisi pola asuh orang tua :

\section{Tabel kisi-kisi pola asuh orang tua}

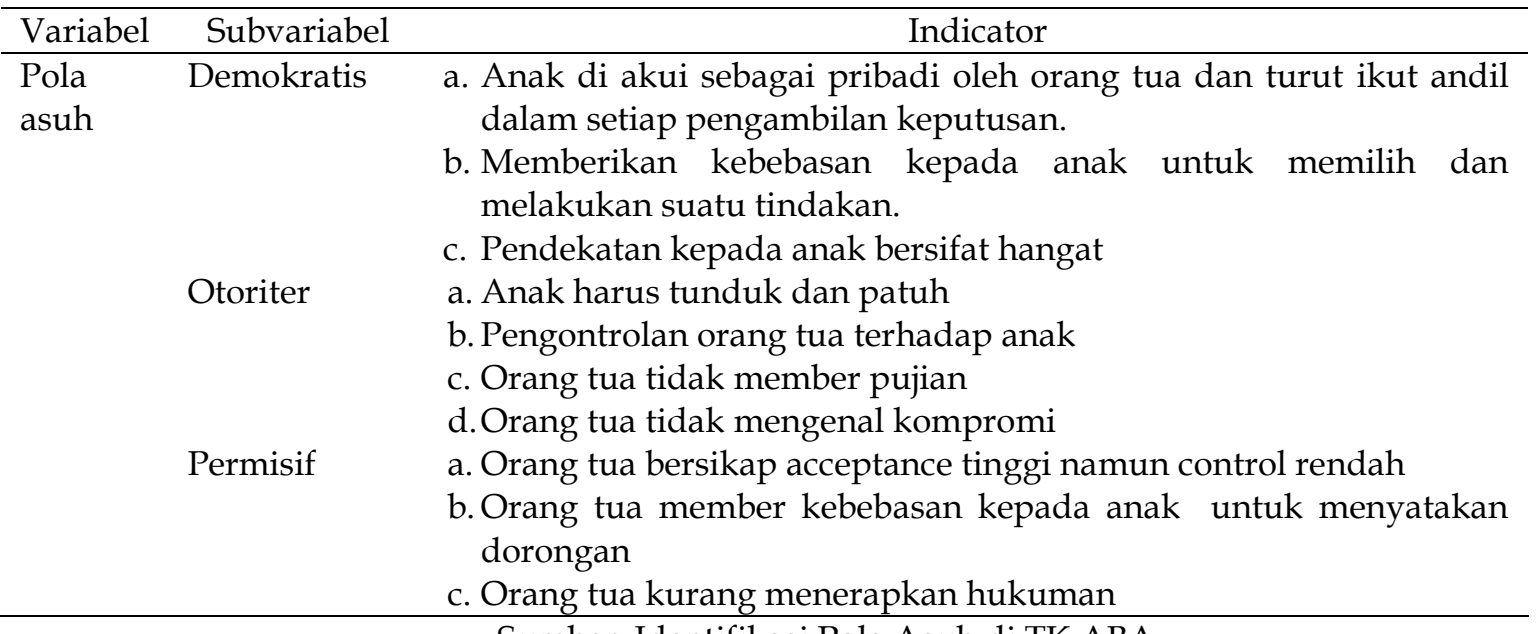

Sumber: Identifikasi Pola Asuh di TK ABA

Teknik analisis data menggunakan metode statistic. Metode ini termasuk kedalam statistic deskriptif. Analisis deskriptif dilakukan untuk mengetahui pola asuh orang tua seperti apa yang sering diterapkan di Kota Pontianak. Dalam mencari pola asuh orang tua dianalisis dengan menghitung rata-rata jawaban berdasarkan hasil scoring setiap jawaban dari responden. Sebelumnya data dibagi terlebih dahulu menurut jenis pola asuhnya. Seelah itu mencari skor maksimal tiap responden. Dengan rumus berikut: 


$$
\text { Skor maksimal }=\frac{\text { total skor }}{\text { jumlah butir soal }} \times 100
$$

Setelah diketahui semua skor maksimal pada tiap-tiap responden dan jenis pola asuhnya, lalu di analisis mana jenis pola asuh yang paling banyak diterapkan orang tua di Kota Pontianak.

\section{HASIL DAN PEMBAHASAN}

Dalam penelitian ini ada satu variable yaitu pola asuh, yang terdiri dari 3 subvariable di antaranya pola asuh demokratis, pola asuh otoriter, dan pola asuh permisif. Dalam variabel tersebut terdapat 11 indikator, berikut ini adalah indikator pola asuh orangtua: Pola asuh demokratis, anak diakui sebagai pribadi oleh orangtua dan turut dilibatkan dalam pengambilan keputusan, memprioritaskan kepentingan anak, akan tetapi tidak ragu mengendalikan mereka, memberikan kebebasan kepada anak untuk memilih dan melakukan suat tindakan,pendekatan kepada anak bersifat hangat.

Pola asuh orang tua otoriter , anak harus mengikuti aturan serta tunduk dan patuh pada kehendak orang tua, pegontrolan orang tua terhadap perilaku anak sangat ketat, orang tua hampir tidak pernah memberikan pujian, orang tua tidak mengenalkompromi dalam komunikasi.

Pola asuh permisif, orangtua bersikap (menerima) namun control terhadap sikap anak rendah, anak diizinkan berbuat berdsarkan kehendak anak sendiri, orang tua member kebebasan kepada anak untuk menyatakan keinginan, orang tua kurang menerapkan hukuman pada anak, hampi r tidak menggunakan hukuman.

Berikut ini adalah hasil penelitian pola asuh orang tua di Kota Pontianak berdasarkan hasil google form yang telah disebar:

Tabel 2. Hasil penelitian pola asuh di Kota Pontianak

\begin{tabular}{ccccl}
\hline $\begin{array}{c}\text { Respond } \\
\text { ke }\end{array}$ & Demokratis & Otoriter & Permisif & \multicolumn{1}{c}{ Dominan } \\
\hline $\mathbf{1}$ & 83,33 & 50 & 33,33 & Demokrasi \\
$\mathbf{2}$ & 50 & 75 & 66,66 & Otoriter \\
$\mathbf{3}$ & 100 & 12,5 & 33,33 & Demokratis \\
$\mathbf{4}$ & 50 & 25 & 88,33 & Persuasive \\
$\mathbf{\ldots}$ & & & & Demokratis \\
\hline $\mathbf{9 0}$ & 83,33 & 37,5 & 0 & \\
\hline
\end{tabular}

Sumber: Hasil penelitian tahun 2020

Table 2 adalah table hasil perhitungan dari setiap pola asuh yaitu ada pola asuh demokratis, pola asuh otoriter dan pola asuh permisif. Yang mengisi angket yaitu ada 90 responden, dari 90 responden tersebut di bandingkan mana yang lebih dominan. Dapat dilihat pada responden 1 total skor jawaban responden untuk pola asuh demokratis ada 83,33 ,sedangkan skor responden untuk pola asuh otoriter ada 50 dan jawaban untuk permisif ada 33,33 dapat di lihat untuk responden 1 lebih dominan ke pola asuh demokratis, sama hal nya dengan reponden ke2 yaitu untuk pola asuh demokratis skor totalnya 50, sedangkan jawaban responden ke 2 untuk otoriter yaitu 75 dan untuk pola asuh permisif 66,66, dapat dilihat untuk responden no 2 pola asuhnya lebih dominan ke pola asuh otoriter. Dan dilihat seterusnya sampai dengan responden ke 90. Selanjutnya dapat di lihat pada table tiga yaitu total presentasi dari ke tiga vairabel yaitu pola asuh demokratis, pola asuh otoriter dan pola asuh permisif. 
Tabel 3. Presentase dari ke 3 Pola Asuh

\begin{tabular}{clll}
\hline No & \multicolumn{2}{c}{ Tipe Pola Asuh } & Presentase \\
\hline 1. & Demokratis & $88,80 \%$ & \\
2. & Otoriter & $4,44 \%$ & \\
3. & Permisif & $6,66 \%$ & \\
& Total & $100 \%$ & \\
\hline
\end{tabular}

Sumber: Hasil penelitian tahun 2020

Pada tabel 3 dapat dilihat pola asuh demokratis, pola asuh otoriter dan pola asuh permisif dengan presentase sebesar 88,80\%, 4,44\% dan 6,66\%. Hasil presentase tersebut diperoleh dari membandingkan hasil yang paling dominan dari ke 90 responden. Untuk selanjutnya mengelompokkan pola asuh dilakukan perbandingan nilai terhadap ke3 pola asuh dalam bentuk diagram presentase berikut.

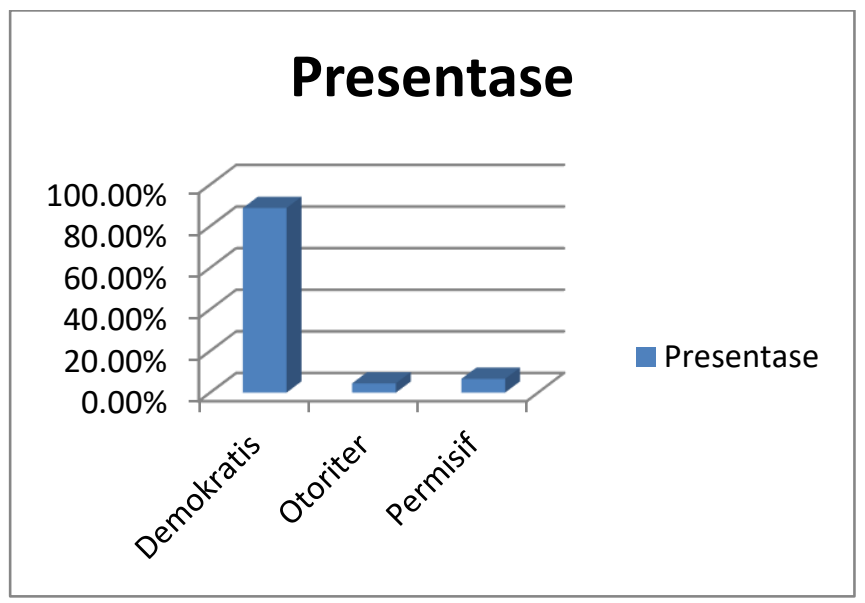

\section{Grafik Presentase Pola Asuh Orang Tua}

Berdasarkan hasil analisis pada table 4 dapat dilihat bahwa dari gambar table presentase di atas dapat dijelaskan pola asuh orang tua di kota Pontianak yang paling dominan adalah pola asuh demokratis dengan presentase $88,80 \%$ yaitu ada sebanyak 80 responden, dimana orang tua mengakui anak sebagai pribadi oleh orang tuaa dan turut dilibatkan dalam pengambilan keputusan, orang tua memprioritaskan kepentingan anak tetapi masih terkontrol, orang tua memberikan kebebasan kepada anak untuk memilih dan melakukan sesuatu tindakan, dan orang tua melakukan pendekatan yang bersifat hangat dengan anak. Sedangkan otoriter ada 4 responden dengan presentase sebesar 4,44\% anak harus patuh akan aturan orang tua, pengontrolan orang tua terhadap perilaku sangat ketat, orang tua hamper tidak pernah member pujian kepada anak, orang tua tidak mengenal kompromi dan pada kondirsi biasanya bersifat satu arah. Sedangkan untuk pola asuh permisif ada 6 responden dengan presentasenya adalah sebesar $6,66 \%$ orang tua bersikap acceptance atau menerima namun control rendah, anak yang di izinkan membuat keputusan sendiri, orang tua cendrung member kebebasan kepada anak untuk menyatakan keinginan, dan orang tua kurang menerapkan hukuman pada anak, hampir tidak ada menggunakan hukuman.

Berdasarkan hasil penelitian secara keseluruhan dapat dilihat bahwa pola asuh demokratis paling banyak di terapkan di Kota Pontianak. Dapat dikatakan Pola asuh demokratis karna orang tua memenuhi keempat indicator pola asuh demokratis yaitu: orang tua mengakui anak sebagai pribadi oleh orang tua dan turut dilibatkan dalam pengambilan keputusan, orang tua memprioritaskan kepentingan anak tetapi masih terkontrol, orang tua memberikan kebebasan kepada anak untuk memilih dan melakukan suatu tindakan, dan orang tua melakukan pendekatan yang bersifat hangat dengan anak. Hasil penelitian (Masni, 
2016) menyatakan bahwa pola asuh demokratis adalah tipe pola asuh yang terbaik dari tipe pola asuh yang lainnya, pola asuh demokratis memperhatikan dan menghargai kebebasan anak, namun kebebasan itu tidak mutlak dan dengan bimbingan yang penuh pengertian antara orang tua dan anak.

Pola asuh demokratis adalah gabungan dari kedua pola asuh yaitu pola asuh permisif dan otoriter dengan tujuan menyamakan pemikiran dan persepsi serta sikap dan tindakan antara anak dan orang tua Dariyo(2011:208). Sejalan dengan penelitian (Bhayangkara \& Raya, 2020)bahwa pola asuh demokratis adalah Pola asuh yang dianggap sebagai pola asuh yang paling baik karena pola asuh demokratis cenderung lebih mendengarkan pendapat sang anak, sifat orang tua seperti inilah yang dibutuhkan anak, walaupun terkenal dengan keramahannya demokratis juga bisa bersikap tegas kepada sang anak namun demokratis mengetahui batasan-batasan anak, pola asuh demokratis terkadang sering menanyakan mengenai keinginan anak,hal tersebut untuk mengetahui apa yang anak butuhkan agar anak merasa diperhatikan, namun terkadang pola asuh demokratis tidak segan menghukum sang anak apabila sang anak melakukan kesalahan akan tetapi pola asuh demokratis akan menjelaskan kesalahan apa yang anak perbuat, apa penyebab sang anak melakukan kesalahan, dan pola asuh demokratis akan menjelaskan cara bertingkah laku yang baik terutama menghormati yang lebih tua. Orang tua yang bersifat demokratis akan mendukung semua kegiatan positif yang anak lakukan, dukungan yang ia berikan berupa kasih sayang, dukungan, dan doa untuk sang anak, ia akan selalu membantu anak jika anak mengalami kesulitan dalam melakukan sesuatu, ia juga akan mendengarkan pendapat anak, dan mereka terkadang bertukar pikiran untuk membangun keluarga yang harmonis. Hasil penelitian (Village et al., 2018) orang tua yang menerapkan pola asuh demokratis akan berpengaruh terhadap kecerdasan interpersonal anak. Kebutuhan anak sangat diperhatikan oleh orang tua dan mencukupinya dengan pertimbangan factor kepnetingan dan kebutuhan realistis. Orang tua juga melakukan pengawasan terhadap aktivitas anak. Orang tua memberikan kebebasan dan rasa tanggung jawab, bahwa anak bisa bertanggung jawab atas apa yang dilakukan anak.

\section{SIMPULAN}

Berdasarkan hasil penelitian dan pembahasan secara keseluruhan dapat disimpulkan bahwa pola asuh yang paling banyak diterapkan di Kota Pontianak adalah pola asuh demokratis karena dari hasil penelitian, orang tua memenuhi keempat indicator pola asuh demokratis yaitu: orang tua mengakui anak sebagai pribadi oleh orang tua dan turut dilibatkan dalam pengambilan keputusan, orang tua memprioritaskan kepentingan anak tetapi masih terkontrol, orang tua memberikan kebebasan kepada anak untuk memilih dan melakukan suatu tindakan, dan orang tua melakukan pendekatan yang bersifat hangat dengan anak.

\section{DAFTAR PUSTAKA}

Bhayangkara, U., \& Raya, J. (2020). Parenting , islamic moral and obedience. Yuarini Wahyu $\begin{array}{lllll}\text { Pertiwi } 1 \text { 1, Amirul } & \text { 2, } & \text { Muminin }\end{array}$ https://doi.org/https://doi.org/10.19109/psikis.v6i1.3921

Candra, A. N., Sofia, A., Anggraini, G. F., Lampung, F. U., Prof, J., \& Brojonegoro, S. (n.d.). No Title, (1). https:// doi.org/https:/ / doi.org/10.1017/CBO9781107415324.004

Dayak, M., \& Kabupaten, H. (2017). Terhadap pendidikan anak, 7, 33-48.

Dewi, K. O. R., Murda, I. N., \& Astawan, I. G. (2020). Hubungan Pola Asuh Orang Tua dan Motivasi Belajar Dengan Hasil Belajar PPKN Siswa, 8, 50-60. https://doi.org/http://dx.doi.org/10.23887/jjpgsd.v8i1.24578

Education, E., Pola, H., Orang, A., Terhadap, T., Bahasa, P., Prasekolah, A., ... Guru, P. (2015). $\begin{array}{llll}\text { Jurnal paud tambusai, } & \text { 42-48), }\end{array}$ https://doi.org/https://doi.org/10.31004/obsesi.v1i1.54

Ekasari, D., \& Witarsa, R. (2018). Pengaruh Pola Asuh Ibu terhadap Kecerdasan Sosial Anak 
Usia Dini di TK Kenanga Kabupaten Bandung Barat, 2(1), 76-84.

Hasanah, N. (2020). Jurnal Obsesi : Jurnal Pendidikan Anak Usia Dini Analisis Pola Asuh Orang Tua terhadap Keterlambatan Bicara pada Anak Usia Dini Abstrak, 4(2), 913-922. https:// doi.org/10.31004/obsesi.v4i2.456

Hazizah, N. (2019).Permisivve parenting effect toward emotional development of early childhood. https:// doi.org/10.24036/kolokium-pls.v7i1.17

Imron, I. (2019). Analisa Pengaruh Kualitas Produk Terhadap Kepuasan Konsumen Menggunakan Metode Kuantitatif Pada CV. Meubele Berkah Tangerang. Indonesian $\begin{array}{llll}\text { Journal on Software Engineering } & \text { (IJSE), 5(1), }\end{array}$ https:// doi.org/10.31294/ijse.v5i1.5861

Kemandirian, D., Sd, A., \& Hidayati, N. I. (2014). Pola Asuh Otoriter Orang Tua , Kecerdasan Emosi , 3(01). https://doi.org/https://doi.org/10.30996/persona.v3i01.364

Masni, H. (2016). Peran Pola Asuh Demokratis Orangtua Terhadap Pengembangan Potensi Diri Dan Kreativitas Siswa. Jurnal Ilmiah Dikdaya, 6(1), 58-74.

Olla, M. B., Helena, N., Daulima, C., Susanti, Y., \& Putri, E. (2018). Enfermería Clínica. Enfermería clínica, 28, 122-125. https://doi.org/10.1016/S1130-8621(18)30050-0

Osborn, K., \& White, B. L. (2018). Analisis faktor oprimalisasi golden age anak usia, 4(1), 4856.

Padjrin, P. (2016). Pola Asuh Anak dalam Perspektif Pendidikan Islam. Intelektualita, 5(1), 1. https:// doi.org/10.19109/intelektualita.v5i1.720

Persepsi, P., Asuh, P., Setelah, P., Program, M., Ibu, S., Calon, D. A. N., \& Banjarmasin, K. (2019). Perubahan persepsi pola asuh peserta setelah mengikuti program sekolah ibu dan calon ibu kota banjarmasin, 3(1), 11-25.

Pratiwi, K. E. (2020). pengaruh pola asuh orang tua terhadap kemandirian anak di sd negeri 38 Kota Parepare The Influence Of Parents on Children 's Independence in Primary School 38 State Parepare City, 1(1).

Rahmah, S. (2019). Pola Komunikasi Keluarga Dalam Pembentukan Kepribadian Anak. $\begin{array}{llll}\text { Alhadharah: } \quad J u r n a l & \text { Ilmu Dakwah, }\end{array}$ https:// doi.org/10.18592/alhadharah.v17i33.2369

Rakhmawati, I. (n.d.). Peran Keluarga dalam Pengasuhan Anak, 6(1), 1-18. https:// doi.org/https:// doi.org/10.21043/kr.v6i1.1037

Santosa, A. I., Rafli, Z., \& Lustyantie, N. (2018). Pengaruh Pola Asuh Orang Tua dan Sikap Bahasa terhadap Kemampuan Membaca Pemahaman The Influence of Parenting Style and Language Attitude toward the Reading Comprehension Achievement, 18(April), 69-80.

Sofiani, I. K., \& Sumarni, T. (2020). Jurnal Obsesi : Jurnal Pendidikan Anak Usia Dini Bias Gender dalam Pola Asuh Orangtua pada Anak Usia Dini Abstrak, 4(2), 766-777. https:// doi.org/10.31004/obsesi.v4i2.300

Sumarni, T., \& Sofiani, I. K. (2019). Pengaruh gawai dalam pola asuh orang tua terhadap anak usia dini ( Studi Kasus Orang Tua dari Anak Usia 5 Tahun di TKIT Ibu Harapan Kecamatan Bengkalis ), 11(1), 96-113. https:/ / doi.org/https:/ / doi.org/10.35445/alishlah.v11i104

Suteja, J. (2017). Dampak pola asuh orang tua terhadap perkembangan sosial emosional anak. https:// doi.org/https:// doi.org/10.24235/awlady.v3i1.1331

Village, W., Regency, L., Nur, Y., \& Sary, E. (2018). Jurnal Obsesi : Jurnal Pendidikan Anak Usia Dini Relationship of Parenting with Child Interpersonal Intelligence in, 2(2), 137142. https://doi.org/10.31004/obsesi.v2i2.93

Vogt, W. (2015). Proportional Stratified Random Sample. Dictionary of Statistics \& Methodology, 02(01). https://doi.org/10.4135/9781412983907.n1534

Yunita, R., Syarifuddin, H., Fitria, Y., Padang, U. N., \& Barat, S. (2020). Jurnal basicedu, 4(3), 571-576. https://doi.org/https:/ / doi.org/10.31004/basicedu. v4i3.390 